THE MASONTOWN KIMBERLITE, FAYETTE COUNTY, PENNSYLVANIA: INSIGHTS INTO EMPLACEMENT PROCESSES BY THE CHARACTERIZATION OF XENOCRYST SIZES AND SHAPES USING COMPUTED TOMOGRAPHY

Brenna G. Cole [1], Graham D.M. Andrews ${ }^{[1]}$, Sarah R. Brown ${ }^{[1]}$, Holly D. Pettus ${ }^{[1]}$, Henry Prellwitz ${ }^{[2]}$

1. Volcanology and Petrology Lab, Department of Geology and Geography, West Virginia University, Morgantown, WV; 2. Allegheny GeoQuest, Pittsburgh, PA

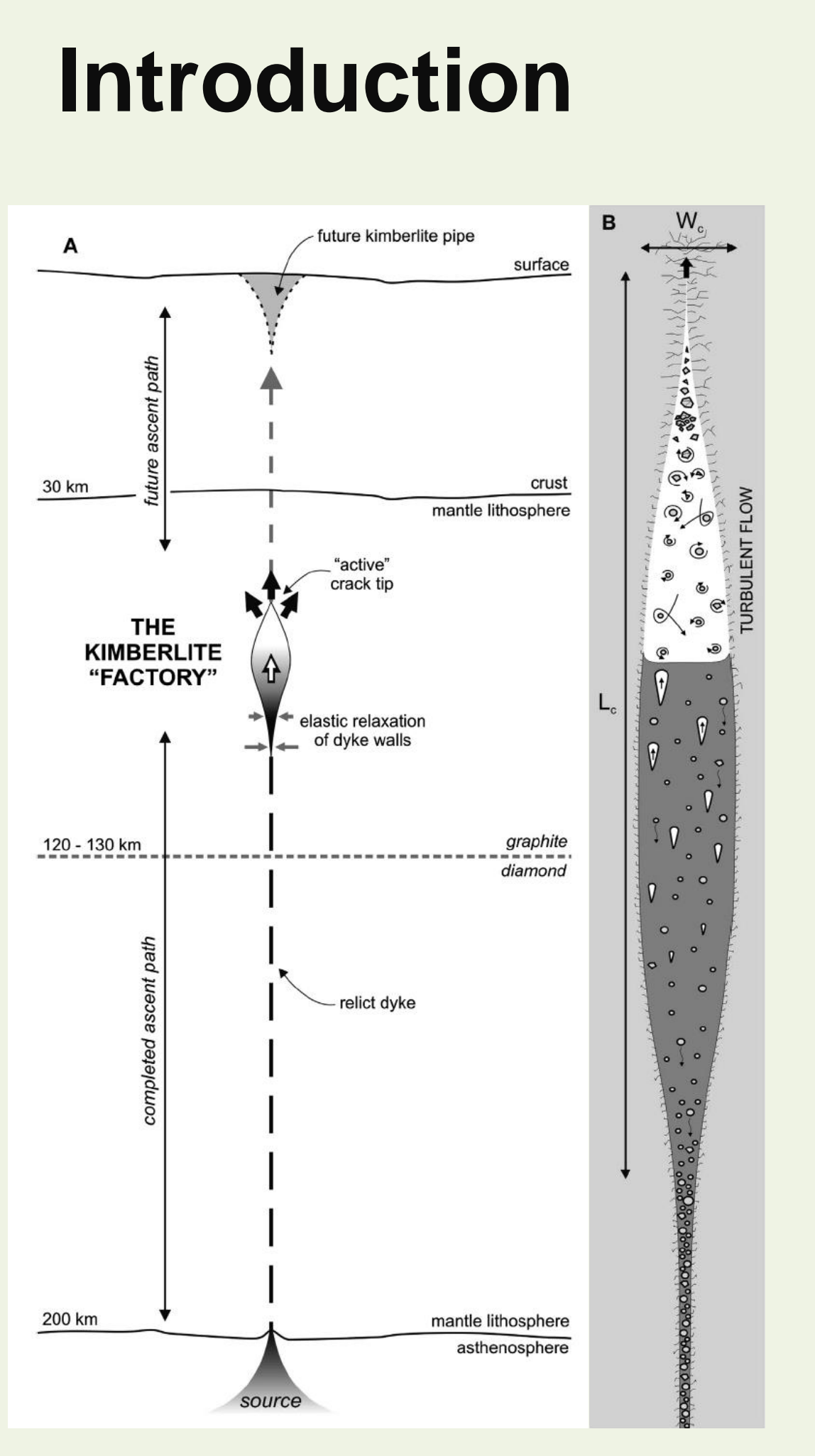

Kimberlite is a mantle-derived ultramafic rock found in dikes an diatremes.

Kimberlites must ascend very quickly because they preserve and they erupt explosively.

How does kimberlite magma ascend through the mantle and the lithosphere?

The KIMBERLITE FACTORY model (Brett et al, 2015) proposes a set of transient head of an ascending kimberlite dike.

1. The dike tip fractures 2. Xenocritosts are freed and decompress.
3. Xenocrysts

3. Xenocrysts
rounded.

4. Xenocrysts are wetted

by melt.

5. Xenocrysts sette
in the dike.

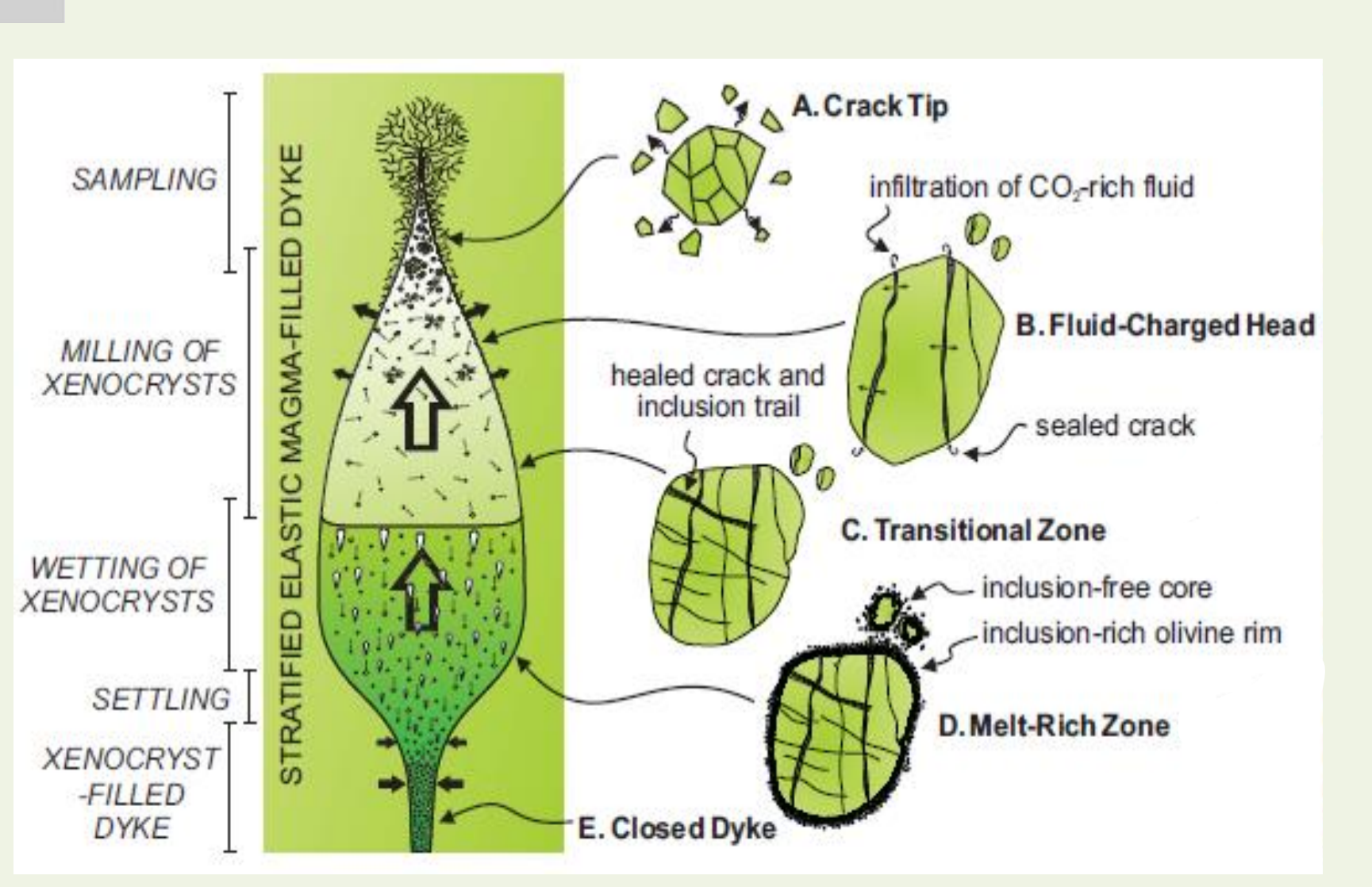

\section{Geologic Background}

- The Jurassic Masontown kimberlite is a 5 - $50 \mathrm{~cm}$ wide dike in Fayette County, PA, emplaced during rifting between North America and Africa County, PA, emplaced during rifting be
(Prellwitz, 1994; Bikerman et al., 1997).

- The kimberlite is olivine-porphyritic with a groundmass of serpentine apatite, calcite, and sulfides.

- Xenocrysts of olivine, phlogopite,
ilmenite (Schultz \& Hearn, 2015) Xenoliths of peridotite, dunite, gabbro, granulite, and limestone
Methodology

3 samples (A-C) were provided by the - Industrial computed X-ray tomography (iCT) scanning performed at NETL

Morgantown.

iCT data provides non-destructive 3D

images of a sample, allowing for

not visible from the outside.

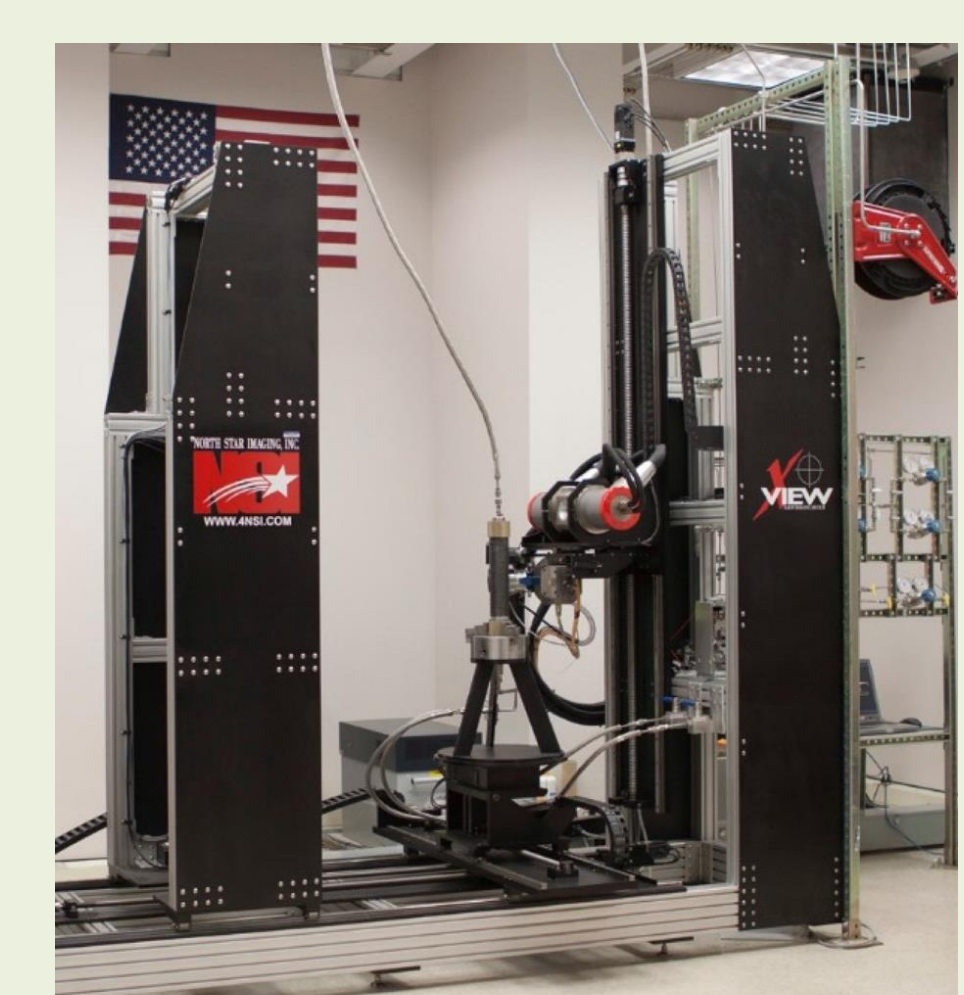

Results: Optical Petrography

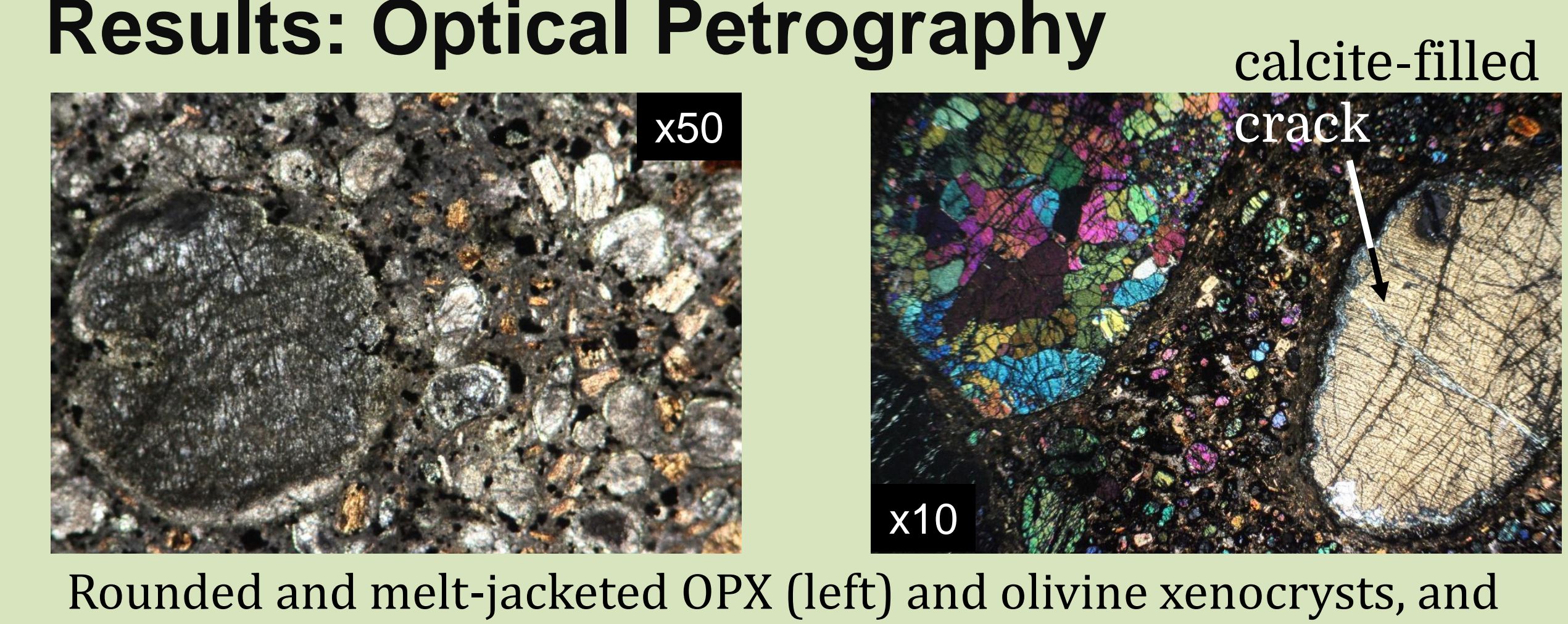

Rounded and melt-jacketed OPX (left) and olivine xenocrysts, and
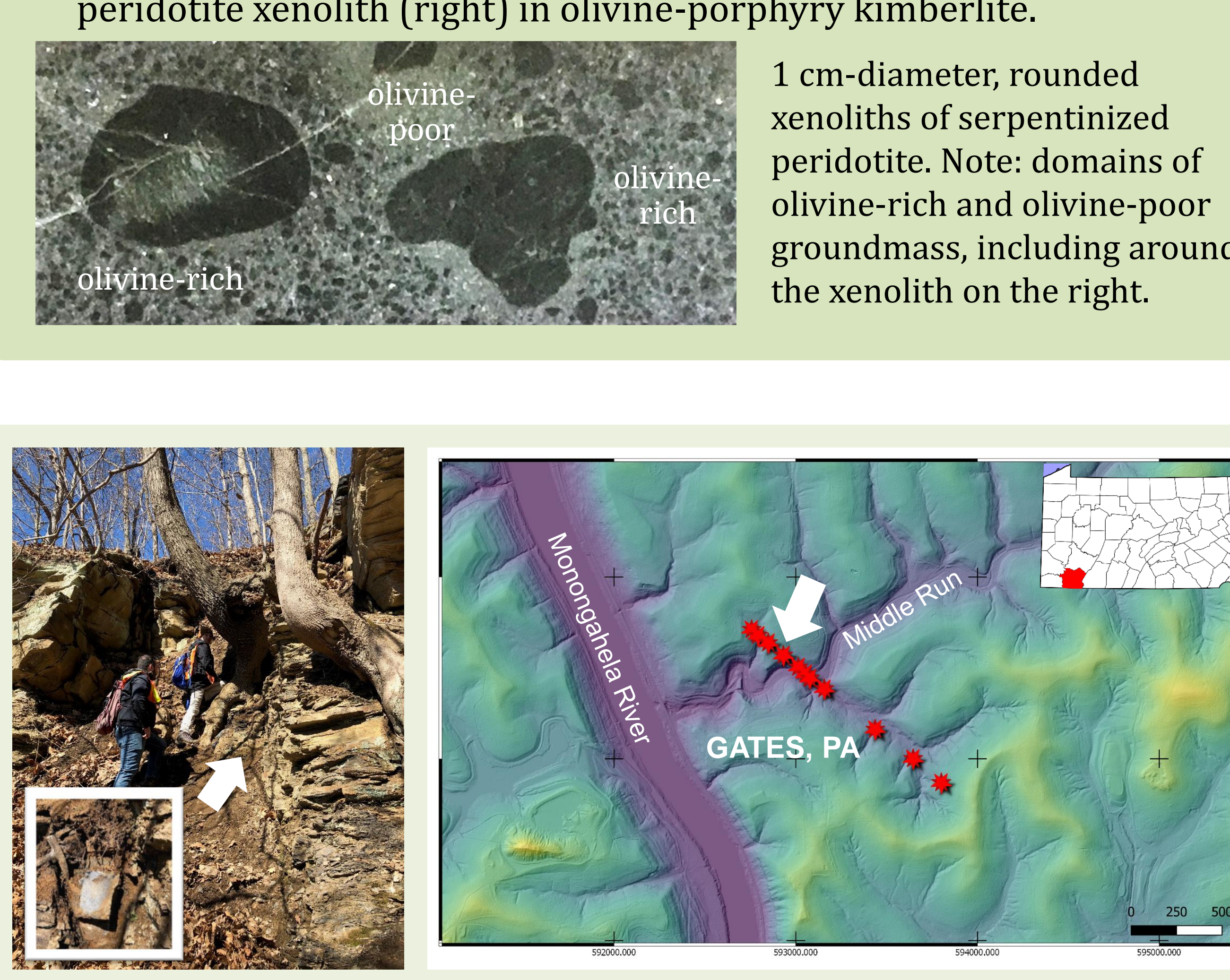

Results: iCT Analysis

Raw iCT data in the form of a grayscale image stack (see A

Brightness and contrast adjustments in FIJ emphasize olivine xenocrysts and regrowth rims (B) while improving grayscale

value consistency th

Segmentation using Ilastik from the groundmass and background (C).

Segmented data can be uploaded to Blob 3D (D) to

Only one or two types of

measurement (e.g. volum

surface area, etc.) were

extracted at a time due to the

large data set size.
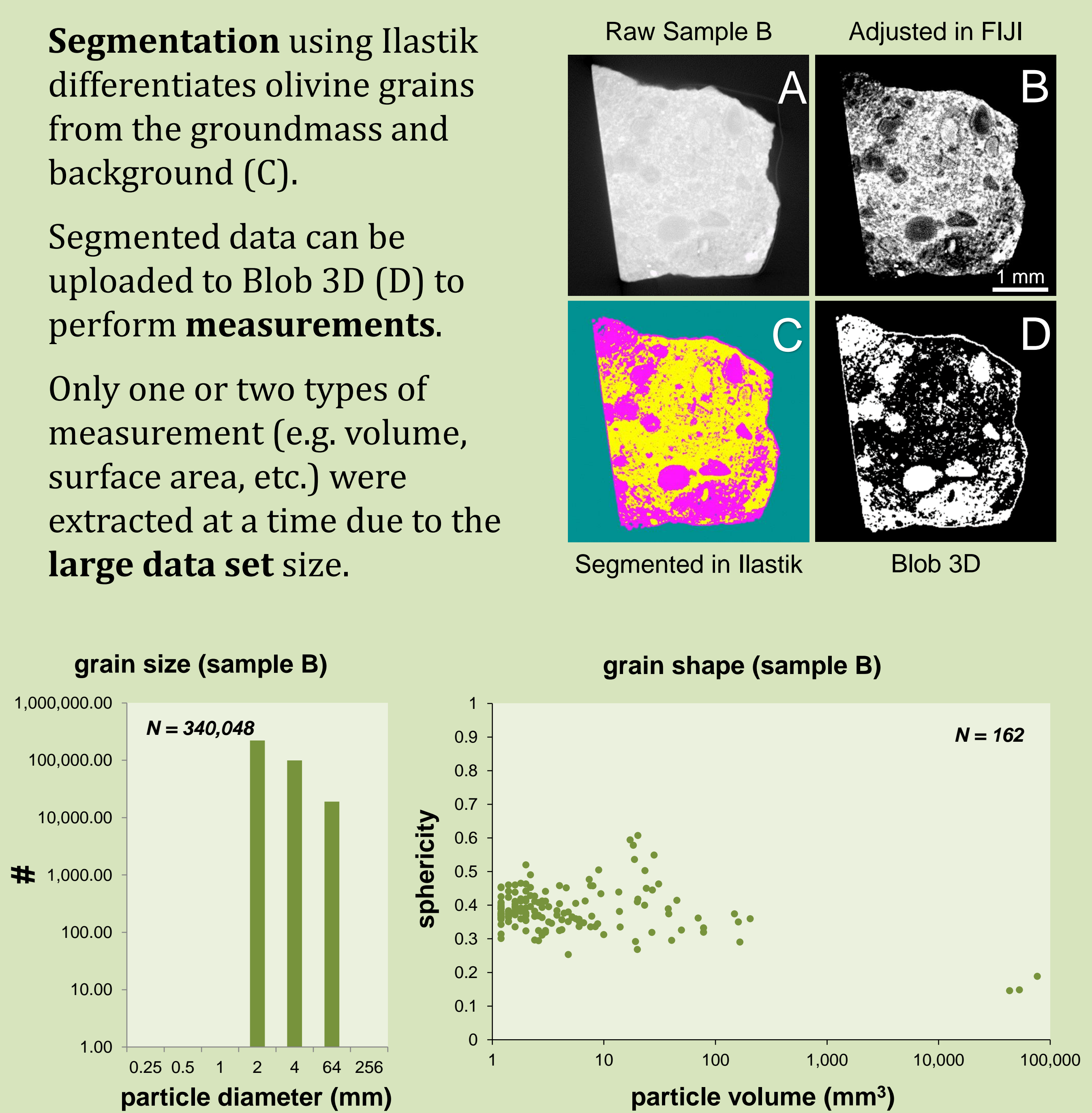

Grain size data from sample B obtained using Blob3D software shows the abundance of 1 to $4 \mathrm{~mm}$-diameter grains (pebble-sized) xenoliths and xenocrystic megacrysts (es phlogopite).

Grain shape data show that megacrysts and xenoliths are very non-spherical (0.1-0.2) compared to moderately spherical grains (i.e. groundmass olivines).
Discussion

iCT analysis provides a wealth of data but is challenging to process and interpret.

CT analysis is used routinely for examining porosity and microstructure in rocks where there is a high density / attenuation contrast between minerals and voids. This is not the case with (S.G. 3.21-3.33) or serpentine (2.5-2.6): only where they occur together does the iCT successfully isolate grains (e.g., sample B).

Results show that grain size and grain shape data can be gathered

relative and volumetric proportions of megacrysts / xenoliths an be estimated from the iCT data.

Conclusions

ICT analysis can be used to estimate measurements of physical

icT data allowed observa

of sample properties that cannot be

The software programs involved are not designed for kimberlite-they work more effectively when there is more - Samples A and C (also from the SI NMNH) lacked sufficient contrast to analyze in the software programs.

Subspherical megacrystic xenocrysts and non-spherical xenoliths both exhibited very rounded textures.

.

Acknowledgements

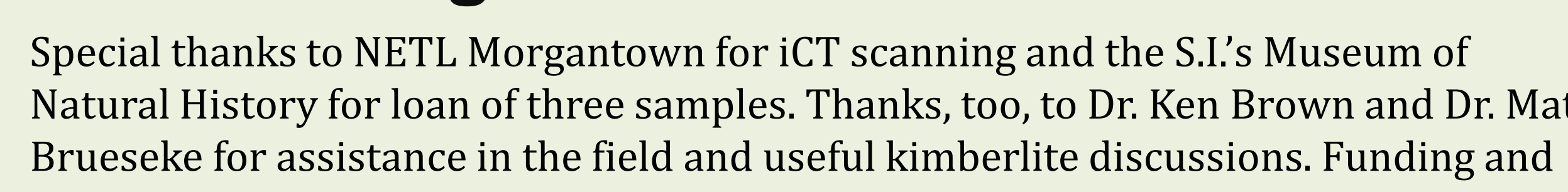

